\title{
Radiant heat transfer reduction methods in heat insulation of power equipment
}

\author{
A. V. Ryzhenkov, S. I. Pogorelov, N. A. Loginova, \\ A. F. Mednikov \& A. B. Tkhabisimov \\ Scientific Research Center "Wear Resistance", \\ National Research University "Moscow Power Engineering Institute", \\ Russia
}

\begin{abstract}
One common challenge for designers of power equipment to be operated at high temperatures is the reduction of radiation heat transfer. As the emissivity factor of radiating heated surfaces of such equipment in most cases can be reasonably approximated by a constant, the power emitted by them is directly proportional to the fourth power of their absolute temperature. A solution of this problem is the use of thermal radiation shields made from low-emissivity and highly reflective materials. Traditionally heat insulation structures employ aluminum foil as such a shield. However, aluminum is soft and rather expensive, and it also has a low tensile strength. An alternative to the use of aluminum foil is the application to the external surface of the thermal insulation structure of a reflective metal layer via ion-plasma spraying (bombardment) in vacuum or metal spraying (metalizing) by means of an electric arc. In order to find out which method of reduction of radiation heat transfer offers the best results, we have compared a number of methods of thermal radiation shielding (foil winding, ion-plasma spraying in vacuum or electric arc wire spraying) in terms of thermal resistance of proper heat insulation structure. In our paper we have used heat insulation structures with thinfilm heat insulation coatings. The experiments were carried out in conditions simulating real conditions of operation of pipelines and power equipment in Russia. The results of the experiments show that the alternative methods of thermal radiation shielding are more efficient than the traditional one (aluminum foil winding). In particular, the use of an aluminum coating applied to the surface of a heat insulation structure via ion-plasma spraying allows the thermal resistance
\end{abstract}


to increase by $35 \%$; in case of metalizing via electric arc wire spraying the thermal resistance increased by $15 \%$ or more.

Keywords: radiation heat transfer, thermal insulation, power equipment, pipelines, shields, thermal resistance, thin-film heat insulating coatings.

\section{Introduction}

In case of power equipment the radiation heat transfer to the environment can account for $25-80 \%$ the total heat loss depending on the temperature [1]. As a rule, in order to reduce the radiation heat loss designers use thermal radiation shields made from materials with high reflection coefficient $(\mathrm{R} \geq 90 \%)$ and low emissivity in the infrared wavelength range $\left(0.8 \cdot 10^{-3} \div 0.8 \mathrm{~mm}\right)$ [2]. Electromagnetic waves interact with the atoms of the thermal radiation shield and their energy is partly transferred into heat energy. Therefore the shield absorbs the energy and is heated; as a heated body it begins to emit electromagnetic waves as thermal radiation. In a simplified model the electromagnetic waves emitted by the shield's external (reciprocal, not contacting the protected source) surface is symbolically regarded as the thermal radiation of the shielded source, which has passed through the shield.

Traditionally heat insulation structures of heat or power equipment and pipelines employ aluminum foil for thermal radiation reflection. However, aluminum is soft and rather expensive, and aluminum foil has a low tensile strength.

An alternative to the use of aluminum foil is the application to the external surface of the thermal insulation structure of a reflective metal layer via ionplasma spraying (bombardment) in vacuum or metal spraying (metalizing) by means of an electric arc.

This study aims at determination of the efficiency of the reduction of radiation heat transfer when using various methods of thermal radiation shielding (aluminum foil winding, ion-plasma spraying and electric arc wire spraying).

\section{Description of the samples used in experiments}

In our experiments we used as samples of heat insulation structures steel cylinders $1100 \mathrm{~mm}$ long with external diameter of $89 \mathrm{~mm}$ with a thin-film heat insulation coating (THIC). The THIC is a syntactic foam made of glass microspheres and an acrylic matrix. It is regarded as a material with good prospects for future use in heat insulation structures of power equipment [3-5]. The THIC layer was $8 \mathrm{~mm}$ thick, i.e. it was thick enough to ensure compliance with sanitary regulations and protection of the workers from burns resulting from contact with hot surfaces.

The reduction of radiation heat transfer from said samples was carried out with the use of aluminum thermal radiation shields produced by the following methods: foil winding, ion-plasma spraying and electric arc wire spraying.

In case of foil winding we used standard aluminum foil $240 \mu \mathrm{m}$ thick.

The ion-plasma spraying of aluminum to said samples has been carried out in a vacuum chamber. The aluminum was deposited at a room chamber. 
In case of electric arc spraying we used two wire electrodes that were melted by an electric arc between them; a jet of compressed air blew and sprayed the molten aluminum.

In both cases, i.e. in plasma spraying and electric arc spraying the thickness of the Al layer was equal to $\sim 10 \mu \mathrm{m}[6]$.

Figure 1 shows typical appearance of the surfaces of the shielded samples.

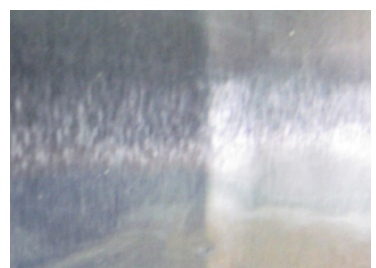

(a)

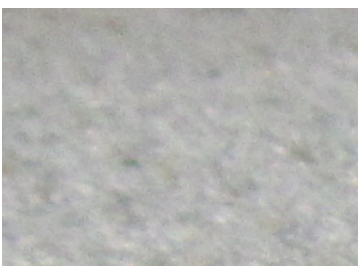

(b)

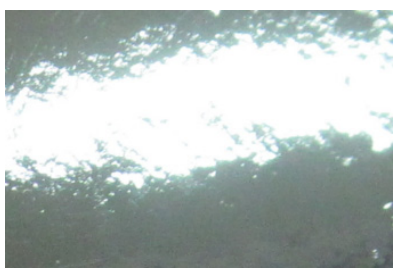

(c)

Figure 1: Typical appearance of the surfaces of the shields: (a) foil winding, (b) surface metalized by means of an electric arc, (c) deposition via ionplasma spraying.

\section{Description of experiments}

The efficiency of the shielding methods has been compared in terms of the thermal resistance of shielded and unshielded test samples. The experiments were carried out on a special test stand in a thermostatic room [7]. Figure 2 shows a conceptual sketch of this test stand.

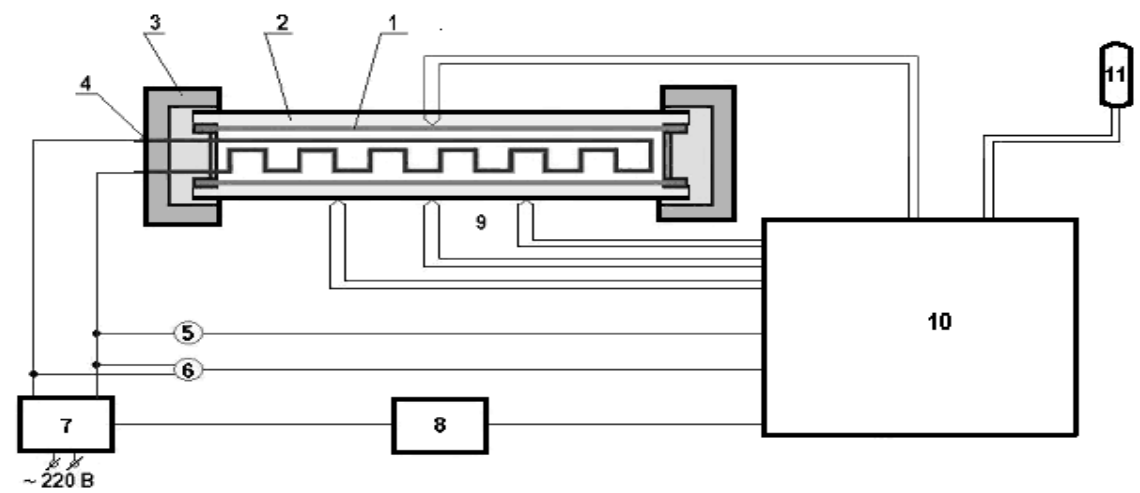

Figure 2: Conceptual sketch of the test stand for determination of the thermal resistance of the samples tested. 1. Steel cylinder, 2. THIC, 3. Cap, 4. Electric heater, 5. Current sensor, 6, Voltage sensor, 7. Power supply unit, 8. Electronic temperature regulator, 9. Thermocouples, 10. Module for measurements and data processing, 11. Climate control system. 
The flat ends of the detachable samples of heat insulation structures consisting of a steel cylinder (1) with a deposited layer of THIC (2) were covered with caps (3) for insuring a homogeneous temperature distribution over the surface of the sample of proper heat insulation structure. The test stand was equipped with current sensors and voltage sensors (6). It was switched on and off with the use of power supply unit (7). The temperature on the surface of steel cylinder 1 was regulated with the use of electronic regulator (8). The temperature on the surface of the samples of heat insulation structures was measured with the use of thermocouple elements (9), positioned in four cross sections (five thermocouples in each of the cross sections). The thermocouples were connected to multichannel module for measurements and data processing (10) that displays temperature, current and voltage values. The parameters of the ambient air in the room are regulated with the use of climate control system (11).

In the course of the experiments we have measured the distribution of the temperature over the surface of the test samples. The temperature on the surface of the steel cylinder was maintained in the range, which is typical for the operation of the equipment and pipelines used in Russian heat supply systems $\left(+110^{\circ} \mathrm{C}-\right.$ $\left.+160^{\circ} \mathrm{C}\right)$.

In order to calculate the thermal resistance we have used equation (1), which is derived from the Fourier's heat conduction equation [8]:

$$
R_{\lambda}=\frac{t_{1}-t_{2}}{q}
$$

where $q$ is the heat flux density, $\mathrm{W} / \mathrm{m}^{2}, \mathrm{t}_{1}, \mathrm{t}_{2}$ is the temperatures on the external surface of the steel cylinder and on the external surface of the test sample, ${ }^{\circ} \mathrm{C}$, respectively.

We have measured the thermal resistance of test samples of heat insulation structures without shielding and of those shielded through aluminum foil winding, ion-plasma spraying and electric arc wire spraying.

\section{Results and their discussion}

The efficiency of heat insulation structures of pipelines and power equipment has been determined in terms of their thermal resistance, i.e. their capacity to reduce the heat transfer to the environment via conduction, convection and radiation.

The total heat resistance of a heat insulation structure is equal to the arithmetical sum of the resistances of the elements connected in series:

$$
R=R_{p}+R_{\text {ins }}+R_{s}
$$

where $R_{p}, R_{\text {ins }}, R_{s}$ is the thermal resistances of the wall of the pipeline or power equipment, heat insulation layer and external surface of the heat insulation structure, respectively.

The thermal resistance of the wall of the pipeline or power equipment $R_{p}$, as well as the thermal resistance of the layer of heat insulation $R_{\text {ins }}$ determine the conduction component of heat transfer. As a rule, pipelines and power equipment 
are made from metal and their thermal resistance is negligible because of the high thermal conductivity coefficient.

The thermal resistance of the layer of heat insulation $R_{\text {ins }}$ was calculated based on the equations derived from the Fourier's equation. In case of a cylindrical wall proper equation can be written as follows:

$$
R_{\text {ins }}=\frac{1}{2 \cdot \pi \cdot \lambda} \ln \frac{d_{2}}{d_{1}}
$$

where $d_{1}, d_{2}$ is the internal and the external diameters of the layer of heat insulation, $\mathrm{m}$ respectively; $\lambda$ is the thermal conductivity coefficient of the layer of heat insulation, $(\mathrm{W} / \mathrm{m} \cdot \mathrm{K})$.

The thermal resistance of the external surface of the heat insulation structure determines both the conduction and the convection components of heat transfer and in case of a cylindrical surface it can be calculated using the following formula:

$$
\mathrm{R}_{\mathrm{s}}=\frac{1}{\pi \cdot \mathrm{d}_{2} \cdot \alpha}
$$

where $\alpha$ is the surface coefficient of heat transfer, $\left(\mathrm{W} /\left(\mathrm{m}^{2} \cdot \mathrm{K}^{4}\right)\right)$.

The coefficient of heat transfer from the external wall to the ambient air is a sum of two components:

$$
\alpha=\alpha_{r}+\alpha_{\mathrm{\kappa}}
$$

where $\alpha_{\mathrm{r}}$ is the radiation heat transfer coefficient; $\alpha_{\mathrm{K}}$ is the convection coefficient.

The radiation heat transfer coefficient was calculated using the StefanBoltzmann's formula:

$$
\alpha_{r}=\mathrm{C} \frac{\left(\frac{t_{2}+273}{100}\right)^{4}-\left(\frac{t_{0}+273}{100}\right)^{4}}{t_{2}-t_{0}}
$$

where $\mathrm{C}$ is the radiation coefficient, $\left(\mathrm{W} /\left(\mathrm{m}^{2} \cdot \mathrm{K}^{4}\right)\right) ; \mathrm{t}_{2}$ is the temperature of the surface, ${ }^{\circ} \mathrm{C}$; $\mathrm{t}_{0}$ is the temperature of the environment ${ }^{\circ} \mathrm{C}$.

In a thermostatic room $\alpha_{\mathrm{K}}$ is negligible and in our approximation it could be set equal to zero.

The radiation coefficient $\mathrm{C}$ for THIC is equal to $\sim 5.0 \mathrm{~W} /\left(\mathrm{m}^{2} * \mathrm{~K}^{4}\right)$, for aluminum $\sim 0.34 \mathrm{~W} /\left(\mathrm{m}^{2} * \mathrm{~K}^{4}\right)$ [2]. If all other conditions are the same, the thermal resistance $R_{S}$ of the external surface of a shielded heat insulation structure (characterizing the efficiency of the reduction of radiation heat transfer) will be higher than the thermal resistance of the unshielded heat insulation structure.

Figure 3 shows the efficiency of various methods of shielding of heat insulation structures in terms of reduction of radiation heat transfer in the temperature range from $+110^{\circ} \mathrm{C}$ to $+160^{\circ} \mathrm{C}$.

In case of thermal insulation materials the thermal conduction coefficient usually increases with increase of temperature. Formula (3) provides evidence that thermal resistance of an unshielded sample of heat insulation structure $\left(\mathrm{R}_{\mathrm{THIC}}\right)$ decreases with increase of temperature, and the results of the experiments have proved it (see $\mathrm{R}_{\mathrm{THIC}}$ in Figure 3 ). 


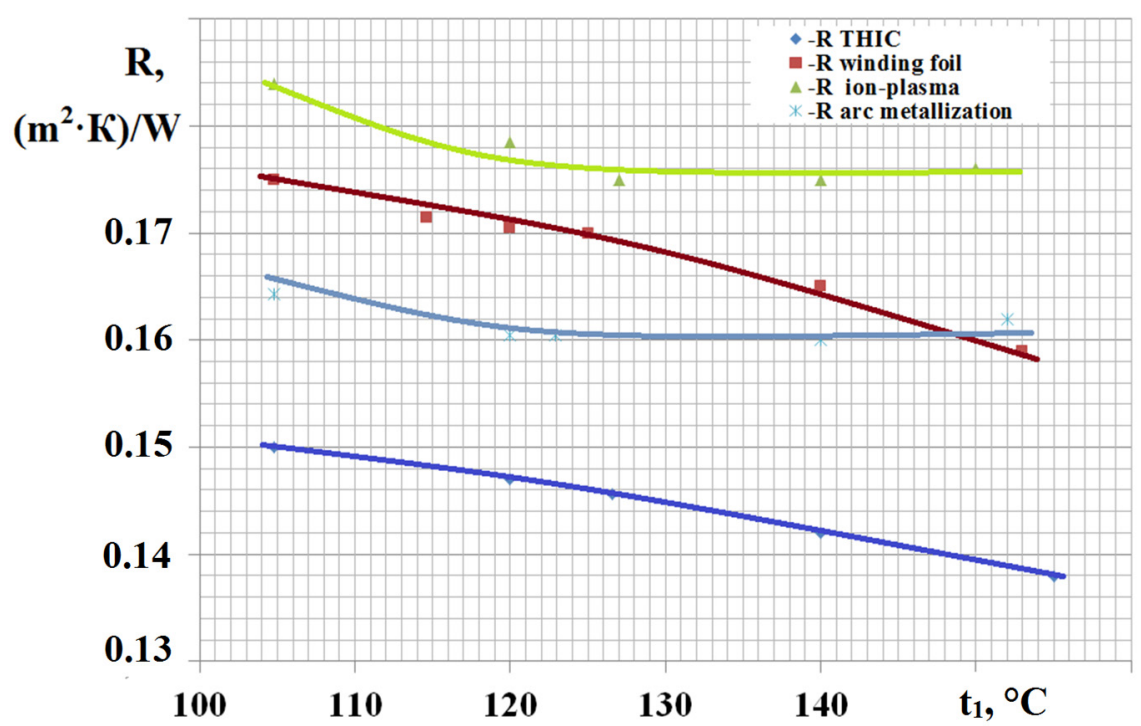

Figure 3: Thermal resistance resulting from the use of various methods of shielding of heat insulation structures.

The trend toward the decrease of thermal resistance also exists in case of the test sample that has been shielded with the use of aluminum foil (see $\mathrm{R}_{\text {winding foil }}$ in Figure 3). Here it is noteworthy to mention that as the temperature increases the shield absorbs more and more energy and, when heated, it begins to emit electromagnetic waves and therefore loses energy so that thermal resistance decreases.

In the temperature range from $110^{\circ} \mathrm{C}$ to $150^{\circ} \mathrm{C}$ the thermal resistance of the test sample of the heat insulation structure that has been shielded via electric arc wire spraying is lower than the thermal resistance of the samples that have been shielded differently (see $\mathrm{R}_{\text {arc metallization }}$ in Figure 3 ). When the metal is deposited via electric arc wire spraying, the surface is rough and therefore the area of contact with the ambient air increases thus leading to enhancement of heat transfer. However, as the temperature of the isolated metal increases, the thermal resistance $\mathrm{R}_{\text {ins }}$ decreases because of the increase of the thermal conductivity of the heat insulation layer, so that heat transfer takes place mainly through radiation.

At a certain stage the specific thermal resistance of the external surface of the heat insulation structure $R_{S}$ exceeds the other component of the total thermal resistance $R$, i.e. the specific thermal resistance $R_{\text {ins. }}$. If the temperature is above $130^{\circ} \mathrm{C}$, we observed a trend toward stabilization of the thermal resistance of the test sample of the heat insulation structure that was shielded via electric arc wire spraying. If the temperature is equal to $150^{\circ} \mathrm{C}$ or higher, the thermal resistance of the heat isolation structure shielded via electric arc wire spraying exceeds the thermal resistance of test samples shielded via aluminum foil winding. This effect is due to a lower (by an order of magnitude) metal content in a shield formed via 
electric arc wire spray if compared with aluminum foil winding. The quantity of heat $\mathrm{Q}$, transferred to the shield during heating is given by the formula:

$$
Q=c_{p} \cdot m \cdot \Delta t
$$

where $c_{p}$ is the specific heat capacity of aluminum, $(\mathrm{kJ} /(\mathrm{kg} \cdot \mathrm{K})) ; \mathrm{m}$ is the mass of the shield, $\mathrm{kg} ; \Delta \mathrm{t}$ is the difference in temperature between the internal and external surfaces of the shield.

The high thermal resistance of the test samples of the heat insulation structure shielded via ion-plasma spraying (see $\mathrm{R}_{\text {ion-plasma }}$ in Figure 3 ), is due to low metal content and higher quality of the shield, whose surface is smooth and brilliant as aluminum, if deposited in vacuum, does not become dull and has a high reflection coefficient [9]. The reflection coefficient of high purity (99.99\%) aluminum equals $93 \%$ [10]. If the temperature is above $130^{\circ} \mathrm{C}$ we also observe stabilization of thermal resistance of the shielded test sample of the heat insulation structure due to the fact that $R_{s}>>R_{\text {ins. }}$.

The test samples of the heat insulation structure that were shielded via ionplasma spraying are the most efficient in terms of reduction of the radiation heat transfer. The use of this method of metallization allows to increase the thermal resistance of the heat insulation structure by $35 \%$ or even more if compared with an unshielded sample.

\section{Conclusions}

We have studied a number of shielding methods (foil winding, ion-plasma spraying and electric arc wire spraying) for reduction of the radiation heat transfer.

The efficiency of various methods of shielding heat insulation structures in terms of reduction of radiation heat transfer is determined by thermal resistance.

The thermal resistance of test samples of the heat insulation structure that were shielded via electric arc wire spraying at the temperatures in the range from $110^{\circ} \mathrm{C}$ to $150^{\circ} \mathrm{C}$ was somewhat lower than in case of other shielding methods because of the high degree of roughness of the surface. If the temperature is above $130^{\circ} \mathrm{C}$ there is a trend toward stabilization of the thermal resistance of the heat insulation structure that has been shielded via electric arc wire spraying because the specific thermal resistance of the external surface of the heat insulation structure $R_{s}$ becomes more significant than the other component of the total thermal resistance $\mathrm{R}$.

At temperatures above $150^{\circ} \mathrm{C}$ the thermal resistance of test samples that were shielded via electric arc wire spraying is higher than the thermal resistance of the samples shielded via aluminum foil winding due to low metal content.

The high thermal resistance of test samples of the heat insulation structure that were shielded via ion-plasma spraying (higher by $35 \%$ or more than the thermal resistance of unshielded samples) is due to both, the high value of the reflection coefficient of the aluminum layer that has been deposited in vacuum and the low content of metal.

The experimental data provide evidence of the efficiency of the shields produced via ion-plasma spraying and electric arc wire spraying in terms of 
reduction of the radiation heat transfer at temperatures above $150^{\circ} \mathrm{C}$ that are typical for operation of power equipment. The ease of manufacture and low consumption of metal are the advantages that allow to regard these shielding methods as having good prospects for their use in heat insulation structures of power equipment in the future.

\section{Acknowledgement}

This research was supported by the Ministry of Education and Science of the Russian Federation under Agreement No.14.574.21.0069 dated June 27, 2014 "Development of a flexible, cost-effective, quickly-mountable, heat-insulating structure for enhancement of the efficiency of heat exchange equipment and pipes" (unique identification number RFMEFI57414X0069).

\section{References}

[1] Grigoriev V.A. Heat power engineering: manual, Energoatomizdat, Moscow, p. 588, 1998.

[2] Isaev S.I. Theory of heat and mass exchange: manual for technical universities, Moscow, p. 683, 1997.

[3] Ryzhenkov V.A., Pristshepov A.F., Loginova N.A., Kondratjev A.P. The influence of microspheres and binder on the heat conductivity of thin-film insulating coatings. Reliability and safety of energy, 3(10), pp. 28-30, 2010.

[4] Volkov A.V., Loginova N.A., Pristshepov A.F. The prospects of the use of thin-film heat insulating coatings for protection of pipelines of heating systems and power equipment. Energy and Sustainability V, WIT Transactions on the Ecology and the Environment Vol. 186. DOI: 10.2495/ESUS140631.

[5] Bing Li. 2011. Effect of microstructure and physical parameters of hollow glass microsphere on insulation performance. Material Letters, http:/www.sciencedirect.com/science/journal/00179310/ DOI: 10.1016/ j.matlet.2011.03.062.

[6] Mubojadjan S.A., Alexandrov D.A., Gorlov D.S. Protective and reinforcement coatings deposited via ion-plasma spraying for blades and other important parts of compressors, Aviation materials and technologies, 5, pp. 71-81, 2012.

[7] ISO 8497:1994 Thermal insulation - Determination of steady-state thermal transmission properties of thermal insulation of circular pipes. ISO 1994, Switzerland, p. 16.

[8] Tsvetkov F.F., Grigorjev B.A. Heat and mass transfer. Textbook for universities. MPEI, Moscow, 2001.

[9] Andreev S.V., Gubanova L.A., Putilin E.S. Instructions for laboratory practicum for the course "Optical coatings", Saint-Petersburg, ITMO, 2001.

[10] EN 573-3-94 Aluminum and aluminum alloys. Chemical composition and aluminum semi-finished products. Part 3. 